\title{
SPERMATIC VEIN TESTOSTERONE IN BOARS DURING PUBERTY
}

\author{
I. H. GARLSON, F. STRATMAN AND E. HAUSER \\ Department of Medicine, The Enzyme Institute, and Meat and Animal Science, \\ University of Wisconsin, Madison, Wisconsin 53706, U.S.A.
}

(Received 9th November 1970)

Summary. Spermatic venous levels of testosterone (androst-4-en-17 $\beta$-ol3 -one) were determined for boars as they entered puberty. It was found that the maximal rate of increase of testosterone production occurs between 78 and 130 days of age in Poland China boars.

\section{INTRODUGTION}

Little attention has been paid to the time of onset of testosterone secretion in boars. Considering the anabolic nature of testosterone, it seems realistic to take account of this factor, particularly if one embarks on dietary studies. Previous studies by Mann (1960) and Mann, Rowson, Short \& Skinner (1967) in pubescent animals, have shown that dietary restriction affects several facets of male reproductive physiology, one of which being plasma testosterone levels. In this paper we describe a study of spermatic vein testosterone levels in pubescent boars using a sensitive thin layer and gas chromatographic method.

\section{MATERIALS AND METHODS}

Boars aged from 78 to 192 days were divided into two groups for this study. The first group of nine animals (from 106 to 192 days of age) was selected in order to determine the maximum level of spermatic vein testosterone that might be encountered and to define the specificity and precision of the determination. The second group of three animals was selected for a serial study of spermatic vein testosterone levels during puberty.

The analysis of testosterone was a modification of that reported for progesterone by Carlson \& Rust (1969).

Blood samples ( 8 to $10 \mathrm{ml}$ ) were drawn from the pampiniform plexus using a heparinized syringe, as described by Lindner (1961a), and immediately centrifuged. The plasma was removed and refrigerated. A 10- $\mu$ l aliquot of $\left[{ }^{3} \mathrm{H}\right] 1-2$, testosterone $(250 \mu \mathrm{Ci})$ of specific activity $100 \mathrm{mCi} / \mathrm{mg}$ diluted to $25 \mathrm{ml}$ with methanol was added to each plasma sample and subsequently extracted by two 25-ml aliquots of ethyl acetate. The organic layers were combined and reduced to dryness. The dry extract was dissolved in a small quantity of chloroform and quantitatively transferred to a thin layer chromatograph plate. Development of the chromatogram was by a system of chloroform and ethyl 
acetate $(13: 1)$. The zone corresponding to testosterone was determined by reference to authentic standards run alongside the unknowns. Elution of the testosterone zone for each extract was with a mixture of equal volumes of methanol and ethyl acetate. To acetylate the testosterone so eluted, the solution was evaporated to dryness and a $0.5-\mathrm{ml}$ mixture of acetic anhydride, pyridine and benzene $(5: 1: 5)$ was added. This mixture was allowed to react for $1 \mathrm{hr}$ at $50^{\circ} \mathrm{C}$. To stop the reaction, $2 \mathrm{ml}$ of methanol was added and the solution was evaporated to dryness. The dry reaction mixture was rechromatographed by thin layer chromatography using a solvent system of ethyl acetate and benzene $(1: 1)$. The testosterone acetate zone was eluted and dried. To remove excess silica gel, a water partition between $2 \mathrm{ml}$ water and $4 \mathrm{ml}$ ethyl acetate was repeated three times. The ethyl acetate layers were combined and evaporated to dryness. The dry extract was dissolved in $100 \mu \mathrm{l}$ of ethyl acetate, followed by removal of $10 \mu \mathrm{l}$ for liquid scintillation counting and calculation of recovery. The remainder was dried and redissolved in $10 \mu$ lof ethyl acetate of which $2 \mu \mathrm{l}$ was injected into the gas chromatograph.

An F and M (Hewlett Packard) model 402, high efficiency gas chromatograph was used for the quantification of testosterone acetate. The chromatography was effected by a $6 \mathrm{ft}$ column of $1 \%$ XE-60 on Gas Chrom $Q$ at a temperature of $220^{\circ} \mathrm{C}$ and a helium flow rate of $53 \mathrm{ml} / \mathrm{min}$. The injection port and flame ionization detector temperature was $230^{\circ} \mathrm{C}$. A standard curve of peak height against testosterone acetate concentration was plotted for the analysis of each series of samples. Each sample assayed was corrected for procedural losses.

The specificity of the method was evaluated by the chromatographic behaviour of testosterone in the extract after treatment with acetic anhydride through two steps of thin-layer chromatography and four different gas chromatograph columns of $1 \% \mathrm{XE}-60,1 \% \mathrm{QF}-1,1 \% \mathrm{SE}-30$ and $3 \% \mathrm{NPGS}$, as compared to that of the $\left[{ }^{3} \mathrm{H}\right]$ testosterone internal standard and authentic standards that were non-labelled. Each testosterone acetate peak quantified was required to have an identical retention time to that of authentic testosterone acetate on all columns. Precision of the method was determined by testosterone analyses of five 5-ml aliquots of plasma obtained from a pooled sample of adult boars.

\section{RESULTS}

Recovery results showed that for twenty-four determinations in this study, an average percentage recovery of $74 \pm 1 \cdot 3$ (S.E.) was obtained. Testosterone analysis of a pooled plasma sample from the internal spermatic vein of adult boars yielded $13.3 \pm 1 \cdot 16$ (S.D.) $\mu \mathrm{g} / 100 \mathrm{ml}$ plasma with a coefficient of variation of $8.7 \%$. Testosterone extracted from the same pool of plasma, and assayed as the acetate, had identical retention times to that of the testosterone acetate reference standard on $6 \mathrm{ft} 1 \%$ XE-60, $1 \%$ QF-1, 3\% NPGS and $1 \%$ SE-30 columns. The lowest level of testosterone that could be detected in an extract was $5 \mathrm{ng}$. Except for the youngest animals, it was observed that testosterone was the major component of the extract.

Spermatic vein testosterone levels found in boars over 106 days of age are 
shown in Table 1. The Poland China strain appeared to have lower testosterone levels than the Yorkshire strain.

Testosterone levels were found throughout serial sampling (Table 2, A, B, C) from Poland China boars of 78 to 143 days of age. In the animals studied, the greatest rate of increase of spermatic testosterone levels appeared to occur between 78 and 130 days of age.

TABLE 1

SPERMATIG VEIN TESTOSTERONE LEVELS IN BOARS

\begin{tabular}{l|c|c}
\hline \multicolumn{1}{c|}{ Animal } & Age (days) & $\begin{array}{c}\text { Testosterone } \\
(\mu g / 100 \mathrm{ml} \text { plasma })\end{array}$ \\
\hline Yorkshire & 106 & $6 \cdot 0$ \\
Yorkshire & 133 & $19 \cdot 0$ \\
Yorkshire & 133 & $12 \cdot 6$ \\
Poland China & 138 & $5 \cdot 5$ \\
Poland China & 182 & $6 \cdot 7$ \\
Poland China & 182 & $14 \cdot 5$ \\
Poland China & 183 & $6 \cdot 0$ \\
Yorkshire & 192 & $17 \cdot 4$ \\
\hline
\end{tabular}

TABLE 2

SERIAL LEVELS OF SPERMATIC VEIN TESTOSTERONE IN BOARS

\begin{tabular}{|c|c|c|c|}
\hline Animal & $(\mu \mathrm{g} / 100 \stackrel{A}{\mathrm{ml} \text { plasma })}$ & $\stackrel{B}{B}(\mu g / 100 \mathrm{ml}$ plasma $)$ & $\frac{C}{(\mu g / 100 \mathrm{ml} \text { plasma })}$ \\
\hline $\begin{array}{l}\text { P } 18-1 \\
P\end{array}$ & $\begin{array}{l}1.8(87) \\
2.7(78) \\
1.3(83)\end{array}$ & $\begin{array}{r}11 \cdot 2(127) \\
7 \cdot 1(118) \\
6 \cdot 0(123)\end{array}$ & $\begin{array}{r}8 \cdot 7(143) \\
8 \cdot 3(134) \\
12 \cdot 1(139)\end{array}$ \\
\hline
\end{tabular}

\section{DISGUSSION}

Testosterone has been isolated and identified in the spermatic venous effluent of young boars (Lindner, 1961b) similar in age to the animals used in our study. This author also established that testosterone was the principal testicular androgen found in the spermatic vein blood, and was not readily detectable in arterial or peripheral blood. We observed little evidence of epitestosterone (androst-4-en-17 $\alpha$-ol-3-one) in the extracts analysed. Previous studies by Lindner (1961c) have shown that epitestosterone, as well as testosterone, can be formed by the inherent enzyme activity of whole blood on androstenedione. This activity was shown by Lindner to be present in the blood of the ox and sheep, but was not found in non-ruminant species such as pig, horse and man.

In boars over 100 days of age, testosterone was found to be the major constituent on the GLC chart. However, in younger boars, a component that had a retention time shorter than that of testosterone or epitestosterone was encountered. No attempt was made to characterize this component. The method of analysis ruled out androstenedione. 
It was concluded that the method described would have adequate precision, speed, and sensitivity needed for studies comprised of large numbers of plasma samples.

\section{REFERENCES}

CARLson, I. H. \& Rust, G. G. (1969) Plasma progesterone levels in pregnant, pseudopregnant and anestrous ferrets. Endocrinology, 85, 623.

LiNDNER, H. R. (1961a) Androgens and related compounds in the spermatic vein blood of domestic animals. I. Neutral steroids secreted by the bull testis. F. Endocr. 23, 139.

LiNDNER, H. R. (196lb) Androgens and related compounds in the spermatic vein blood of domestic animals. III. Species-linked differences in the metabolism of androstenedione in blood. F. Endocr. 23, 161 ,

LiNDNER, H. R. (1961c) Androgens and related compounds in the spermatic vein blood of domestic animals. IV. Testicular androgens in the ram, boar and stallion. $\mathcal{F}$. Endocr. 23, 171.

ManN, T. (1960) Effect of nutrition on androgenic activity and spermatogenesis in mammals. Proc. Nutr. Soc. 19, 15.

Mann, T., Rowson, L. E. A., Short, R. V. \& Skinner, J. D. (1967) The relationship between nutrition and androgenic activity in pubescent twin calves, and the effect of orchitis. F. Endocr. 38, 455. 